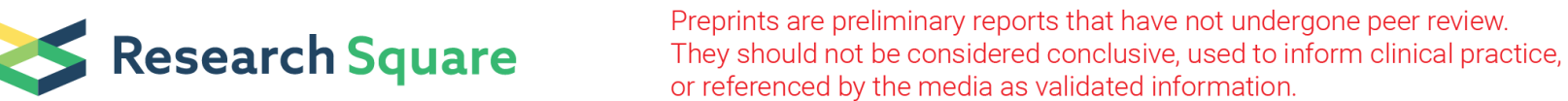

\section{Standard protocols for immune profiling of peripheral blood leucocyte subsets by flow cytometry using DuraClone IM reagents}

\section{Katharina Kronenberg}

Department of Surgery, University Hospital Regensburg, Germany

\section{Paloma Riquelme ( $\sim$ Paloma.Riquelme@ukr.de)}

Department of Surgery, University Hospital Regensburg, Germany https://orcid.org/0000-0001-89623156

\section{James A. Hutchinson}

Department of Surgery, University Hospital Regensburg, Germany https://orcid.org/0000-0002-11994210

\section{Method Article}

Keywords: Flow Cytometry, Immune monitoring, DuraClone, IM Phenotyping Basic Tube, IM T cell subsets Tube, IM TCRs Tube, IM Granulocytes Tube, IM Dendritic Cells Tube, IM B cells Tube, IM Treg Tube

Posted Date: March 4th, 2021

DOI: https://doi.org/10.21203/rs.3.pex-757/v1

License: (1) This work is licensed under a Creative Commons Attribution 4.0 International License. Read Full License 


\section{Abstract}

This document describes standard protocols used by the Hutchinson group for profiling human peripheral blood leucocytes by flow cytometry analyses using DuraClone IM reagents.

\section{Introduction}

This document describes standard protocols used by the Hutchinson group for analysis of human blood leucocyte populations by flow cytometry (1). DuraClone reagents are dry pre-formulated antibody panels for extensive phenotyping of T cells, B cells, NK cells, dendritic cells and granulocytes in whole blood. In our experience, DuraClone IM Tubes are a convenient, reliable and highly standardised option for immune monitoring of clinical trials. In part, these protocols were adapted from the publications of Streitz, Kverenland and colleagues (2-3), as well as manufacturer's recommendations issued by Beckman Coulter.

\section{Reagents}

\section{Reagents}

DuraClone IM Phenotyping Basic Tube (B53309, Beckman Coulter)

DuraClone IM T cell subsets Tube (B53328, Beckman Coulter)

DuraClone IM TCRs Tube (B53340, Beckman Coulter)

DuraClone IM Granulocytes Tube (B88651, Beckman Coulter)

DuraClone IM Dendritic Cells Tube (B53351, Beckman Coulter)

DuraClone IM B cells Tube (B53318, Beckman Coulter)

DuraClone IM Treg Tube (B53346, Beckman Coulter)

VersaLyse Solution (A09777, Beckman Coulter)

DPBS without $\mathrm{Ca}^{2+}$ or $\mathrm{Mg}^{2+}$ (D8537, Sigma)

IOTest 3 Fixative Solution (10x) (A07800, Beckman Coulter)

FBS South American (10270106, Thermo Fisher), heat-inactivated

Ecotainer Aqua B, Distilled water (0082423E, Braun) 
PerFix-nc Kit (B31168, Beckman Coulter)

\section{Materials}

S-Monovette ${ }^{\circledR}$ 2,7 ml, K3 EDTA (05.1167, Sarstedt)

$15 \mathrm{ml}$ tube, $\mathrm{PP}, 17 / 120 \mathrm{~mm}$, conical bottom (188271, Greiner Bio-One)

\section{Equipment}

\section{Equipment}

Navios cytometer: Standard configuration with 10 colours, 3 lasers (Beckman Coulter)

Cytometry List Mode Data Acquisition and Analysis Software (Beckman Coulter)

Kaluza analysis software v.1.3 (Beckman Coulter)

\section{Procedure}

\section{Preparation of reagents}

1.1 Preparation of $0.8 \%$ IOTest 3 Fixative Solution

1. Dilute $100 \mu$ I IOTest 3 Fixative Solution (10X) with $900 \mu$ PBS to obtain $0.8 \%$ IOTest 3 Fixative Solution

\subsection{Preparation of $0.1 \%$ IOTest 3 Fixative Solution}

1. Dilute $12.5 \mu$ IOTest 3 Fixative Solution (10X) with $987.5 \mu$ PBS to obtain $0.1 \%$ IOTest 3 Fixative Solution

1.3 Preparation of $1 X$ PerFix-nc Buffer 3

1. Prepare a $1 / 10$ dilution of $10 X$ Buffer 3 in $\mathrm{ddH}_{2} \mathrm{O}$ : dilute 1 part $10 \mathrm{X}$ Buffer 3 with 9 parts of $\mathrm{ddH}_{2} \mathrm{O}$ 
1. Collect peripheral blood samples directly into EDTA-vacutainers

2. Samples can be stored at $4^{\circ} \mathrm{C}$ for a maximum of $4 \mathrm{~h}$ before processing

3. Mix the blood sample by repeatedly inverting the vacutainer

4.

4.1. For DuraClone IM Phenotyping Basic, T cell, TCRs and Granulocytes Tube: transfer $100 \mu$ blood into the DuraClone Tube

4.2. For DuraClone IM Dendritic Cells Tube: transfer $200 \mu$ blood into the DuraClone Tube

5. Vortex tube for 8 seconds

6. Incubate at room temperature in the dark for $15 \mathrm{~min}$

7. Add $2 \mathrm{ml}$ VersaLyse Solution

8. Vortex tube for 3 seconds

9. Incubate at room temperature in the dark for $15 \mathrm{~min}$

10. Pellet cells by centrifugation at $200 \mathrm{~g}$ for $5 \mathrm{~min}$

11. Aspirate supernatant using a vacuum pump

12. Vortex tube for 3 seconds

13. Add 3 ml DPBS

14. Pellet cells by centrifugation at $200 \mathrm{~g}$ for $5 \mathrm{~min}$

15. Aspirate supernatant using a vacuum pump

16. Resuspend cell pellet in $380 \mu \mathrm{l} 0.8 \%$ IOTest 3 Fixative Solution for data collection using a Navios flow cytometer

\section{Sample preparation using DuraClone IM Tubes: B cells}

1. Collect peripheral blood samples directly into EDTA-vacutainers

2. Samples can be stored at $4^{\circ} \mathrm{C}$ for a maximum of $4 \mathrm{~h}$ before processing

3. Mix the blood sample by repeatedly inverting the vacutainer 
4. Transfer $10 \mathrm{ml}$ DPBS into a $15 \mathrm{ml}$ conical bottom tube

5. Add $300 \mu \mathrm{l}$ blood to the $10 \mathrm{ml}$ DPBS

6. Mix by inverting the tube

7. Pellet cells by centrifugation at $300 \mathrm{~g}$ for $10 \mathrm{~min}$

8. Aspirate supernatant using a vacuum pump

9. Vortex tube for 3 seconds

10. Add $10 \mathrm{ml}$ DPBS

11. Mix by inverting the tube

12. Pellet cells by centrifugation at $300 \mathrm{~g}$ for $5 \mathrm{~min}$

13. Aspirate supernatant using a vacuum pump

14. Resuspend cell pellet in DPBS to get a final volume of $300 \mu \mathrm{l}$

15. Transfer $100 \mu \mathrm{l}$ of washed blood sample into the DuraClone IM B cells Tube

16. Vortex tube for 8 seconds

17. Incubate at room temperature in the dark for $15 \mathrm{~min}$

18. Add 2 ml VersaLyse

19. Vortex for 3 seconds

20. Incubate at room temperature in the dark for $15 \mathrm{~min}$

21. Pellet cells by centrifugation at $200 \mathrm{~g}$ for $5 \mathrm{~min}$

22. Aspirate supernatant using a vacuum pump

23. Vortex tube for 3 seconds

24. Add 3 ml DPBS

25. Pellet cells by centrifugation at $200 \mathrm{~g}$ for $5 \mathrm{~min}$

26. Aspirate supernatant using vacuum a pump

27. Resuspend cells in $380 \mu \mathrm{l} 0.1 \%$ IOTest 3 Fixative Solution for data collection using a Navios flow cytometer 


\section{Sample preparation using DuraClone IM Tubes: Tregs}

1. Collect peripheral blood samples directly into EDTA-vacutainers

2. Samples can be stored at $4{ }^{\circ} \mathrm{C}$ for a maximum of $4 \mathrm{~h}$ before processing

3. Mix the blood sample by repeatedly inverting the vacutainer

4. Transfer $50 \mu \mathrm{l}$ blood into the DuraClone IM Treg Tube 1

5. Vortex for 8 seconds

6. Incubate at room temperature in the dark for $15 \mathrm{~min}$

7. Add $3 \mathrm{ml}$ DPBS

8. Pellet cells by centrifugation at $500 \mathrm{~g}$ for $5 \mathrm{~min}$

9. Aspirate supernatant using vacuum pump

10. Vortex for 3 seconds

11. Add $50 \mu$ l heat-inactivated FCS

12. Mix by pipetting

13. Add $5 \mu$ l PerFix-nc Buffer 1

14. Vortex for 8 seconds

15. Incubate at room temperature in the dark for $15 \mathrm{~min}$

16. Add $400 \mu$ l PerFix-nc Buffer 2

17. Vortex for 8 seconds

18. Transfer content of DuraClone IM Treg Tube 1 into DuraClone IM Treg Tube 2 by pipetting

19. Vortex Tube 2 for 8 seconds

20. Incubate at room temperature in the dark for $60 \mathrm{~min}$

21. Add $3 \mathrm{ml}$ DPBS

22. Incubate at room temperature in the dark for $5 \mathrm{~min}$ 
23. Pellet cells by centrifugation at $500 \mathrm{~g}$ for $5 \mathrm{~min}$

24. Aspirate supernatant using a vacuum pump

25. Vortex for 3 seconds

26. Add $3 \mathrm{ml} 1 \mathrm{X}$ PerFix-nc Buffer 3

27. Pellet cells by centrifugation at $500 \mathrm{~g}$ for $5 \mathrm{~min}$

28. Aspirate supernatant using a vacuum pump

29. Resuspend cells in $380 \mu \mathrm{l} 1 \mathrm{X}$ PerFix-nc Buffer 3 for data collection using a Navios flow cytometer

\section{Analysis of data obtained using DuraClone IM Tubes}

Template manual gating strategies for extracting leucocyte subset frequencies from flow cytometry data using Kaluza software are given in Figure 1 to 7 . Analyses are ideally performed by experienced operators blinded to clinical outcomes.

Fig. 1 DuraClone IM Phenotyping Basic Tube

Fig. 2 DuraClone IM T cell subsets Tube

Fig. 3 DuraClone IM TCRs Tube

Fig. 4 DuraClone IM Granulocytes Cells Tube

Fig. 5 DuraClone IM Dendritic Cells Tube

Fig. 6 DuraClone IM B cells Tube

Fig. 7 DuraClone IM Treg Tube

\section{Troubleshooting}

\section{Time Taken}

\section{Anticipated Results}

\section{References}


1. Hutchinson, JA. Predicting Early Viral Control under Direct-Acting Antiviral Therapy for Chronic Hepatitis C Virus Using Pretreatment Immunological Markers. Front Immunol. 7;9:146 (2018)

2. Kverneland, AH. Age and gender leucocytes variances and references values generated using the standardized ONE-Study protocol. Cytometry A. 89(6):543-64 (2016)

3. Streitz, M. et al. Standardization of whole blood immune phenotype monitoring for clinical trials: panels and methods from the ONE study. Transplant Res. 25;2(1):17 (2013)

\section{Acknowledgements}

\section{Figures}

\section{Gating Strategy for the DuraClone IM Phenotyping Basic Tube}

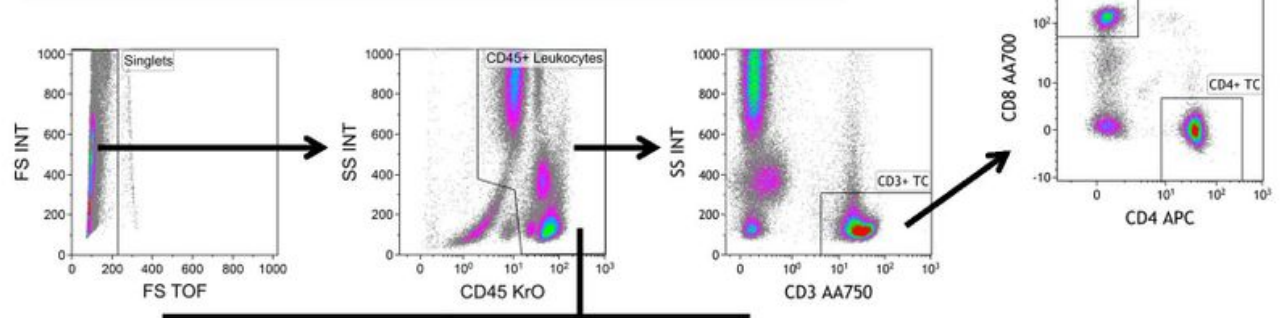

Boolean Gates:

Leucos $=$ CD45+ Leucocytes

Granulos $=$ Granulocytes

Lin $=(C D 3+T C)$ OR $(C D 19+B C)$

$\mathrm{OR}(\mathrm{CD} 6+\mathrm{NKC})$
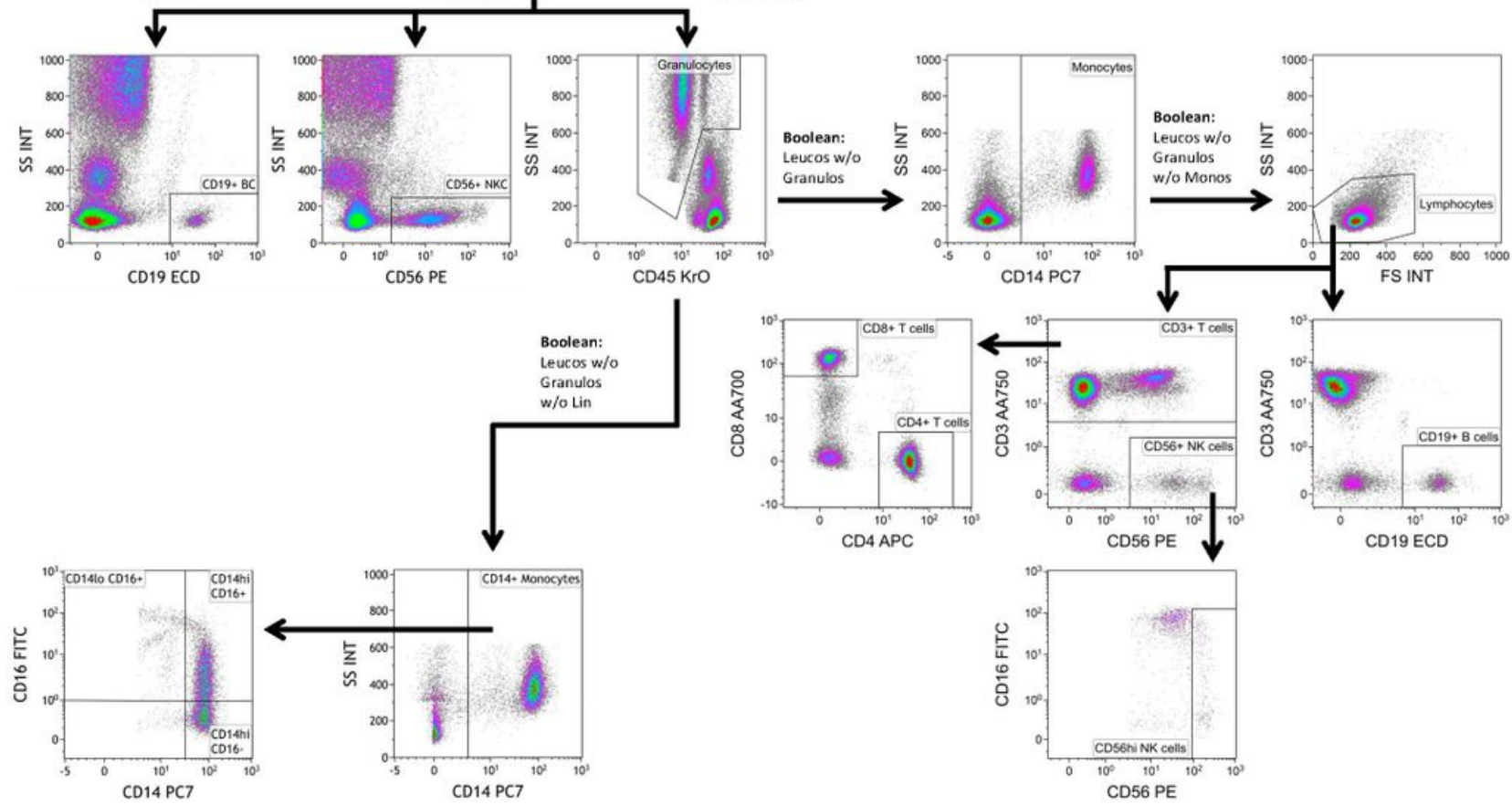

\section{Figure 1}

DuraClone IM Phenotyping Basic Tube 
Gating Strategy for the DuraClone IM T cell subsets Tube
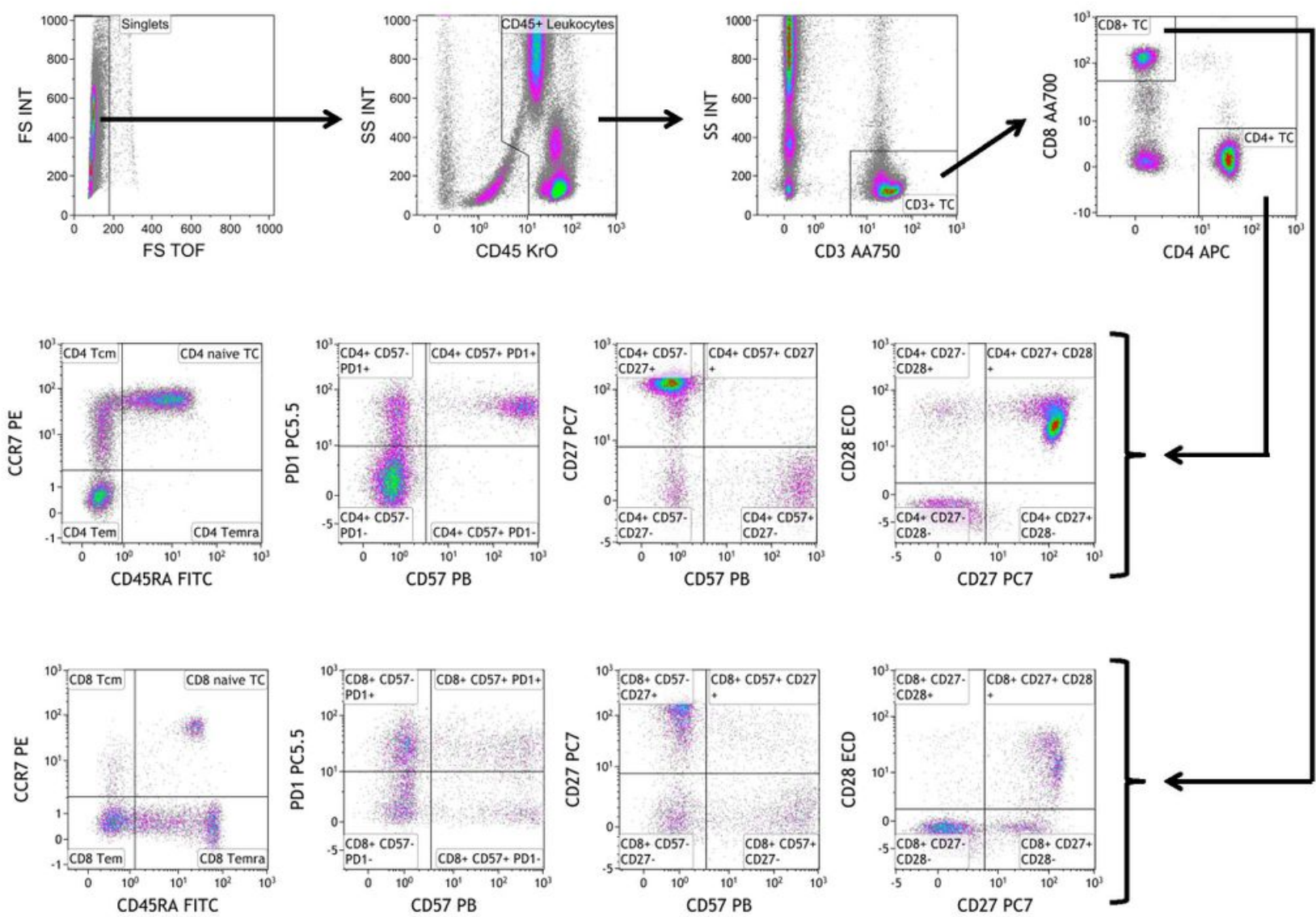

Figure 2

DuraClone IM T cell subsets Tube 
Gating Strategy for the DuraClone IM TCRs Tube
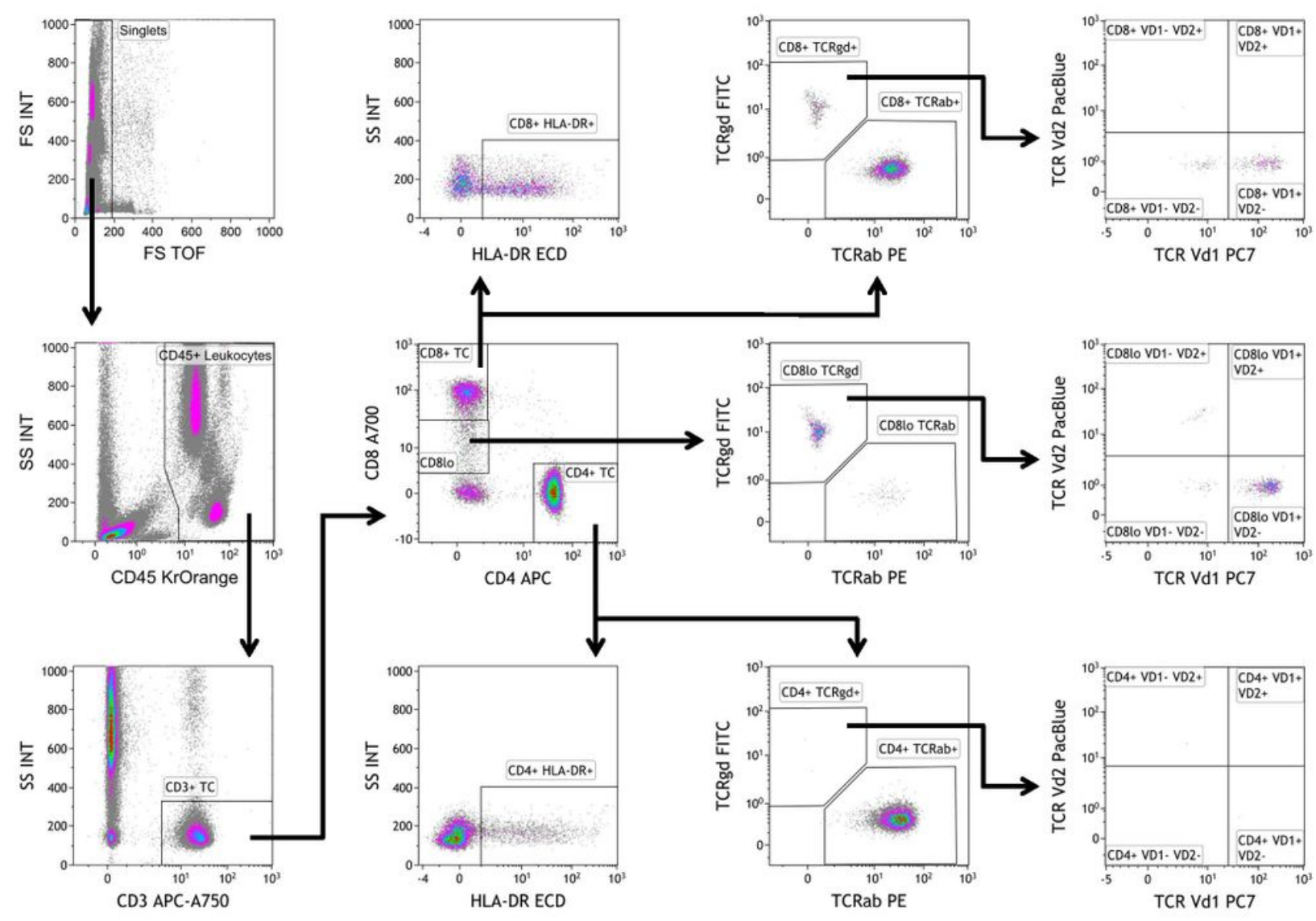

\section{Figure 3}

DuraClone IM TCRs Tube 


\section{Gating Strategy for the DuraClone IM Granulocytes Tube}
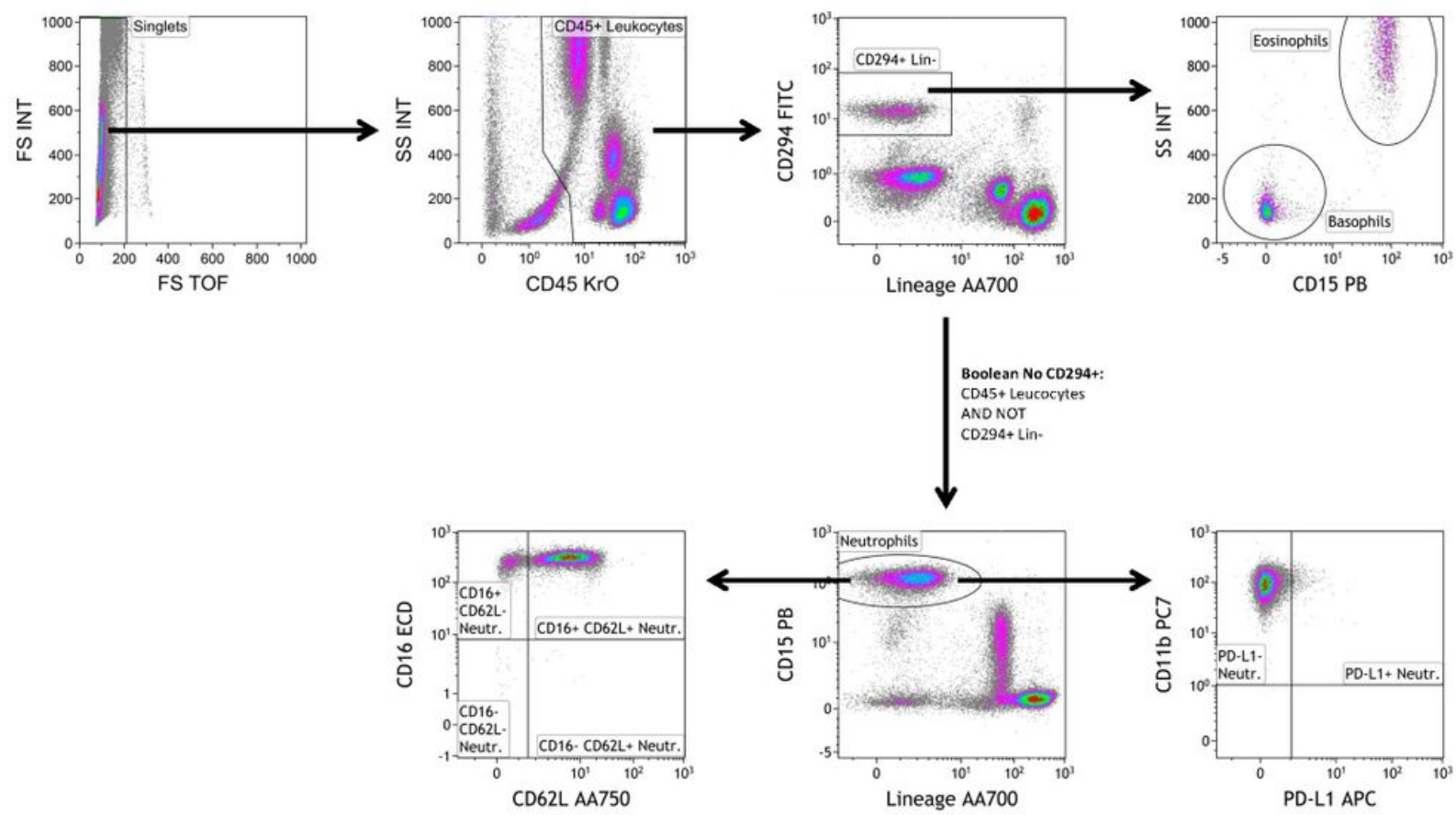

\section{Figure 4}

DuraClone IM Granulocytes Cells Tube 
Gating Strategy for the DuraClone IM Dendritic Cells Tube
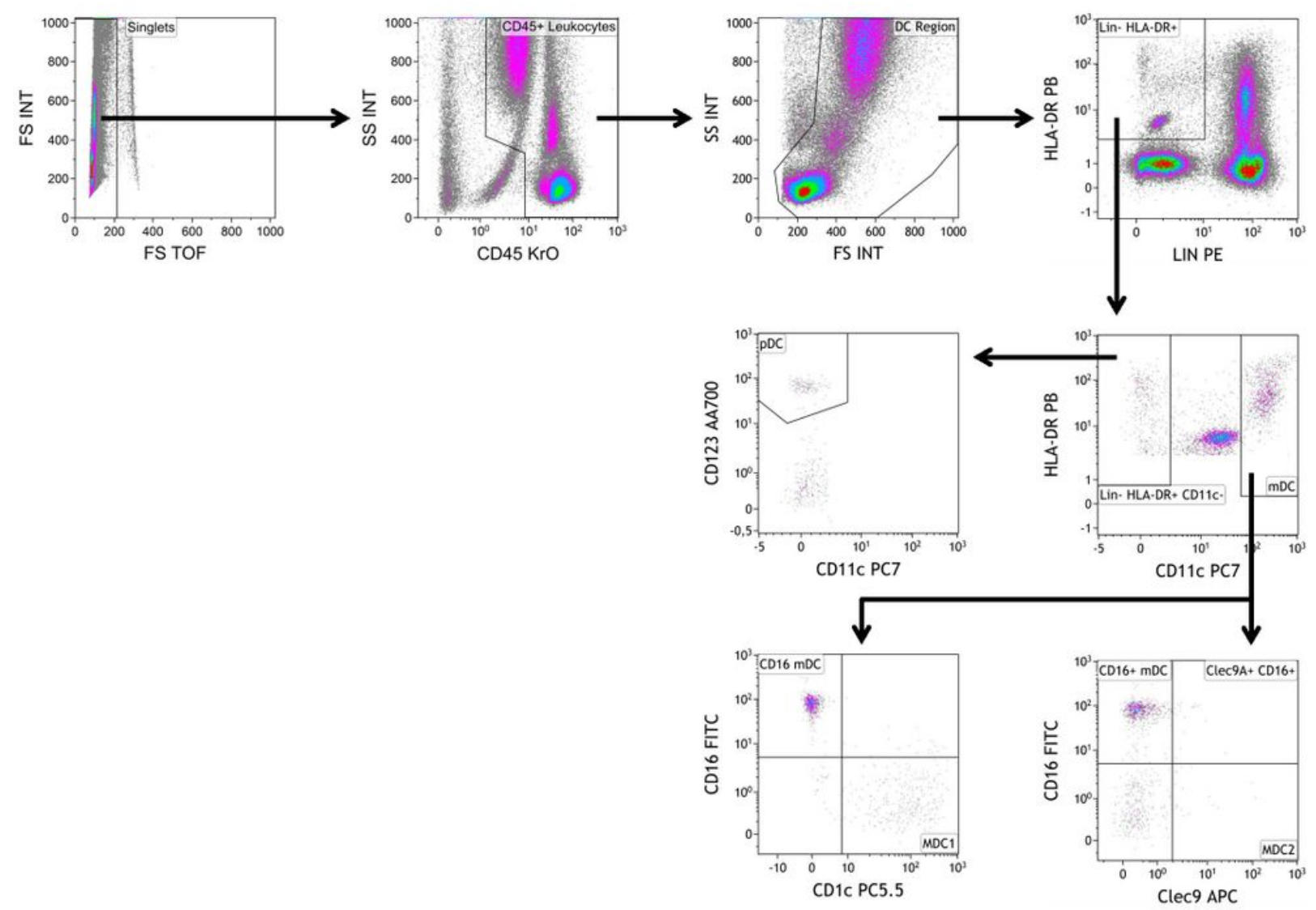

\section{Figure 5}

DuraClone IM Dendritic Cells Tube 
Gating Strategy for the DuraClone IM B cells Tube
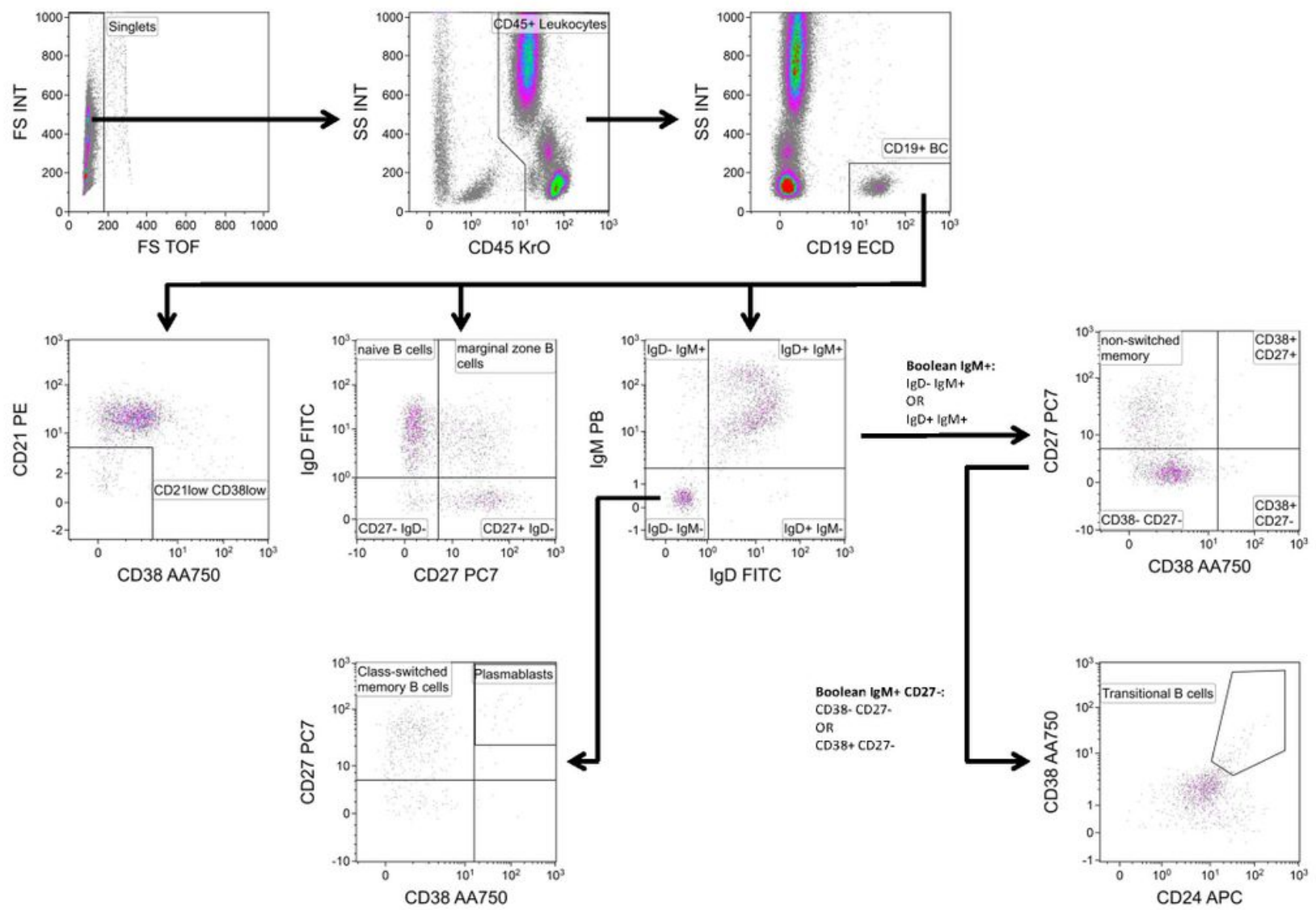

Figure 6

DuraClone IM B cells Tube 


\section{Gating Strategy for the DuraClone IM Treg Tube}
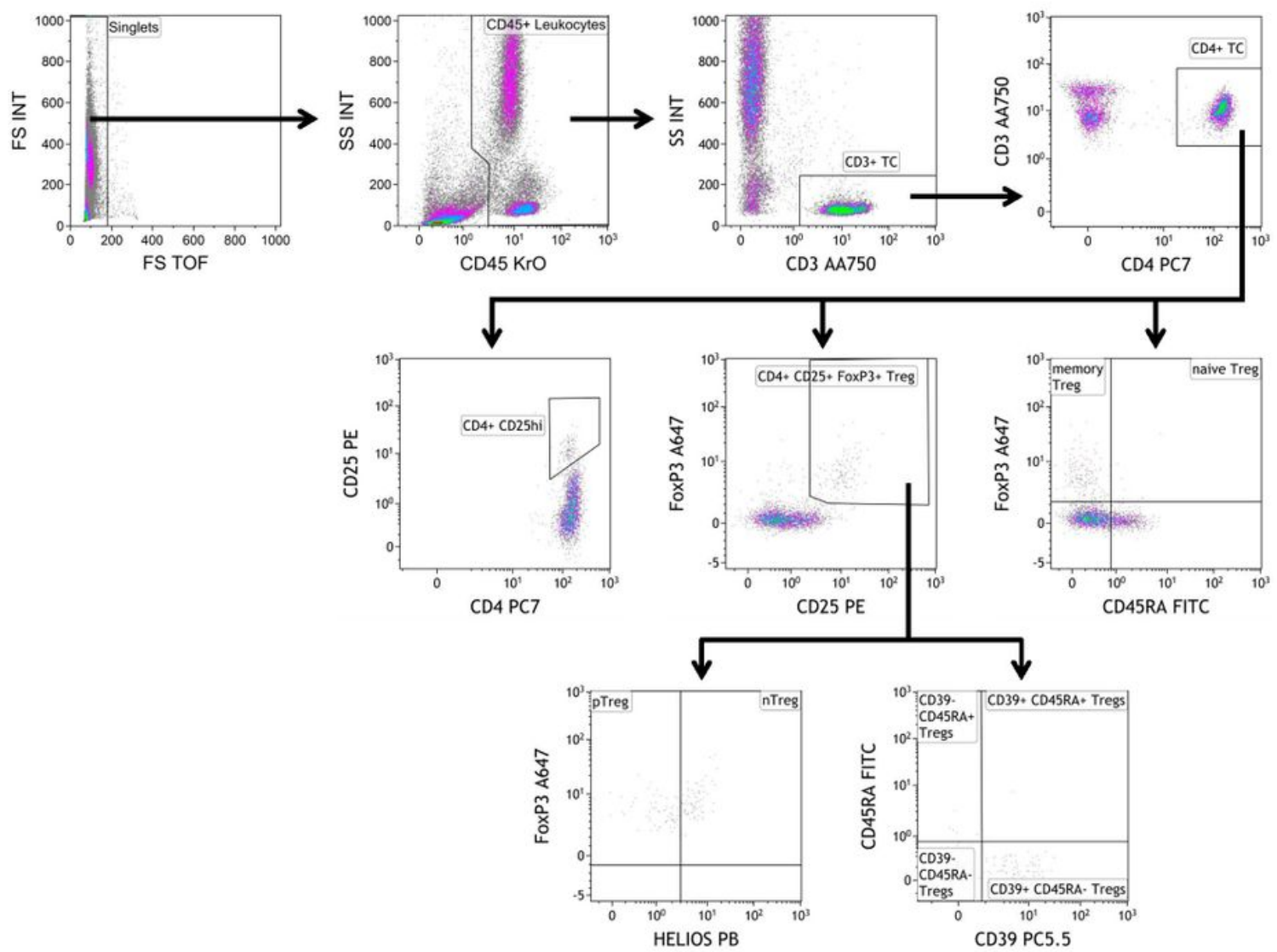

Figure 7

DuraClone IM Treg Tube 